\title{
ANALISIS DAN IMPLEMENTASI SISTEM INFORMASI PENJUALAN BERBASIS WEB PADA UKM TIARA CAKERY BATAM
}

\author{
Indah Kusuma Dewi *1, Okta Veza ${ }^{2}$, Nuraini ${ }^{3}$ \\ 1,2,3Jln Tengku Umar Lubuk Baja Kota Batam Kepulauan Riau 29432. Telp. (0778)425391. \\ ${ }^{1,2,3}$ Program Studi Teknik Informatika, STT Ibnu Sina, Batam \\ e-mail: ${ }^{* 1}$ indah@stt-ibnusina.ac.id, ${ }^{2}$ okta@ stt-ibnusina.ac.id, ${ }^{3}$ 1410128262029@ @stt- \\ ibnusina.ac.id
}

\begin{abstract}
Abstrak
Penelitian ini bertujuan membantu Usaha Kecil Menengah (UKM) Tiara Cakery Batam melakukan penjualan produk secara online. Objek penelitian ini membuat website untuk memudahkan customer melakukan pembelian produk tanpa mendatangi langsung lokasi penjualan. Aplikasi penjualan online ini memberikan pelayanan yang baik untuk customer sehingga melihat langsung gambar serta harga produk melalui aplikasi ini dan dapat memesan produk tersebut dari mana saja. Perancangan apilkasi ini menggunakan metode SDLC ( software development life Cycle ), digambarkan dengan DFD (Data flow diagram),PHP sebagai bahasa pemrograman, MySQL sebagai basis data, dan Macromedia Dreamweaver sebagai editor HTML. Penelitian ini diharapkan dapat dikembangkan dalam versi android.
\end{abstract}

Kata Kunci-UKM, Penjualan Online, SDLC

Abstract

This study aims to help Small and Medium Enterprises (SME) Tiara Cakery Batam to sell products online. The object of this research is creating a website to make it easier for customers purchase products without visiting the sales location directly. This online sales application provides good service for customers so that they can see the pictures and prices of products directly through this application and can order these products from anywhere. The design of this application uses the SDLC method (software development life cycle), described by DFD (Data flow diagram), PHP as a programming language, MySQL as a database, and Macromedia Dreamweaver as an HTML editor. This research is expected to be developed in the Android version.

Keywords—SME, Online Sales, SDLC

\section{PENDAHULUAN}

UKM Tiara Cakery bergerak di bidang penjualan kue oleh-oleh kota Batam dengan berbagai macam jenis kue. Diantaranya adalah Lapis Legit dengan berbagai varian rasa, Roll Cake, Tiramissu dan kue kering lebaran. Dalam waktu satu bulan UKM Tiara cakery Batam dapat menjual produk sekitar 150 pcs untuk produk Lapis Legit, 120 pcs untuk produk Roll cake, dan 80 pcs untuk produk Tiramissu. Dari penjualan semua produk kue pada UKM ini, Omset yang didapat pada setiap bulannya sekitar Rp. 44 Juta. Jumlah pelanggan pada UKM Tiara Cakery Batam sekitar 250 pelanggan baik di kota Batam maupun diluar kota Batam. 


\section{METODE PENELITIAN}

\subsection{Defenisi Analisis}

Analisis adalah penguraian suatu pokok atas berbagai bagiannya dan penelaahan bagian itu sendiri, serta hubungan antar bagian untuk memperoleh pengertian yang sesuai dan pemahaman arti keseluruhan.

\subsection{Pengertian Implementasi}

Implementasi adalah tindakan-tindakan yang dilakukan baik oleh individuindividu/pejabat-pejabat atau kelompok-kelompok pemerintah atau swasta yang diarahkan pada tercapainya tujuan-tujuan yang telah digariskan dalam keputusan kebijakan.

2.3 Pengertian sistem informasi

Sistem informasi adalah sejumlah komponen (manusia, komputer, teknologi informasi, dan prosedur kerja), ada sesuatu yang diproses (data menajdi informasi), dan dimaksudkan untuk mencapai suatu sasaran atau tujuan.

\subsection{Pengertian Penjualan}

Penjualan adalah Penerimaan yang diperoleh dari pengiriman barang dagangan atau dari penyerahan pelayanan dalam bursa sebagai barang pertimbangan. Pertimbangan ini dapat dalam benuk tunai peralatan kas atau harta lainnya. Pendapatan dapat diperoleh pada saat penjualan, karena terjadi pertukaran, harga jual dapat ditetapkan dan bebannya diketahui.

\section{HASIL DAN PEMBAHASAN}

Penelitian ini dilakukan pada bulan April 2018 hingga bulan Agustus 2018 pada UKM Tiara Cakery Batam yang beralamat di Jalan Merak, Cluster Merak KDA Batam Center, Batam Kepulauan Riau.

\subsection{Aliran Sistem Informasi Lama}

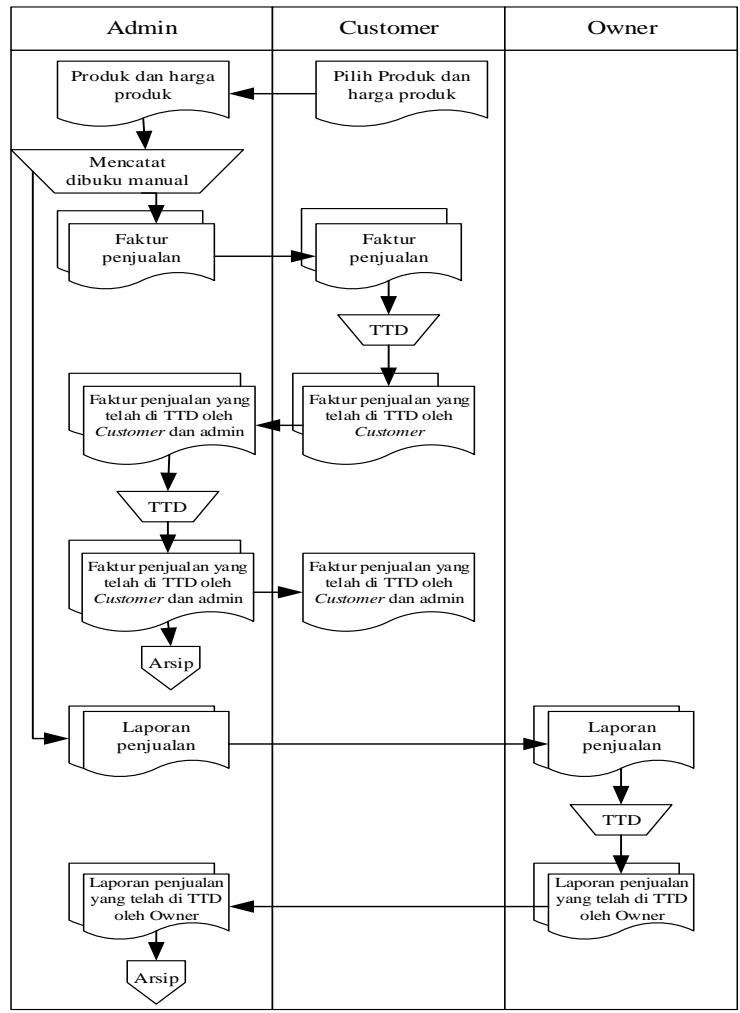

Gambar 1 Aliran Sistem Informasi Lama

Desember 2018 | Vol. 2 | No. 2 | ISSN : 2614-7602 
Aliran sistem informasi yang sedang berjalan pada UKM Tiara Cakery adalah sebagai berikut :

1. Customer datang ke UKM Tiara Cakery

2. Customer melihat-lihat produk yang ada pada toko

3. Costomer mengambil produk yang akan dibeli

4. Setelah barang diambil, customer datang ke meja admin

5. Admin mencatat barang yang dibeli customer

6. Admin memberi faktur penjualan pada customer

7. Customer menandatangani faktur penjualan

8. Admin menandatangi faktur penjualan dan memasukannya ke arsip

9. Admin memberikan laporan penjualan pada owner

10. Owner menandatangani laporan penjualan

11. Admin memasukan laporan penjualan ke dalam arsip

\subsection{Aliran Sistem Informasi Baru}

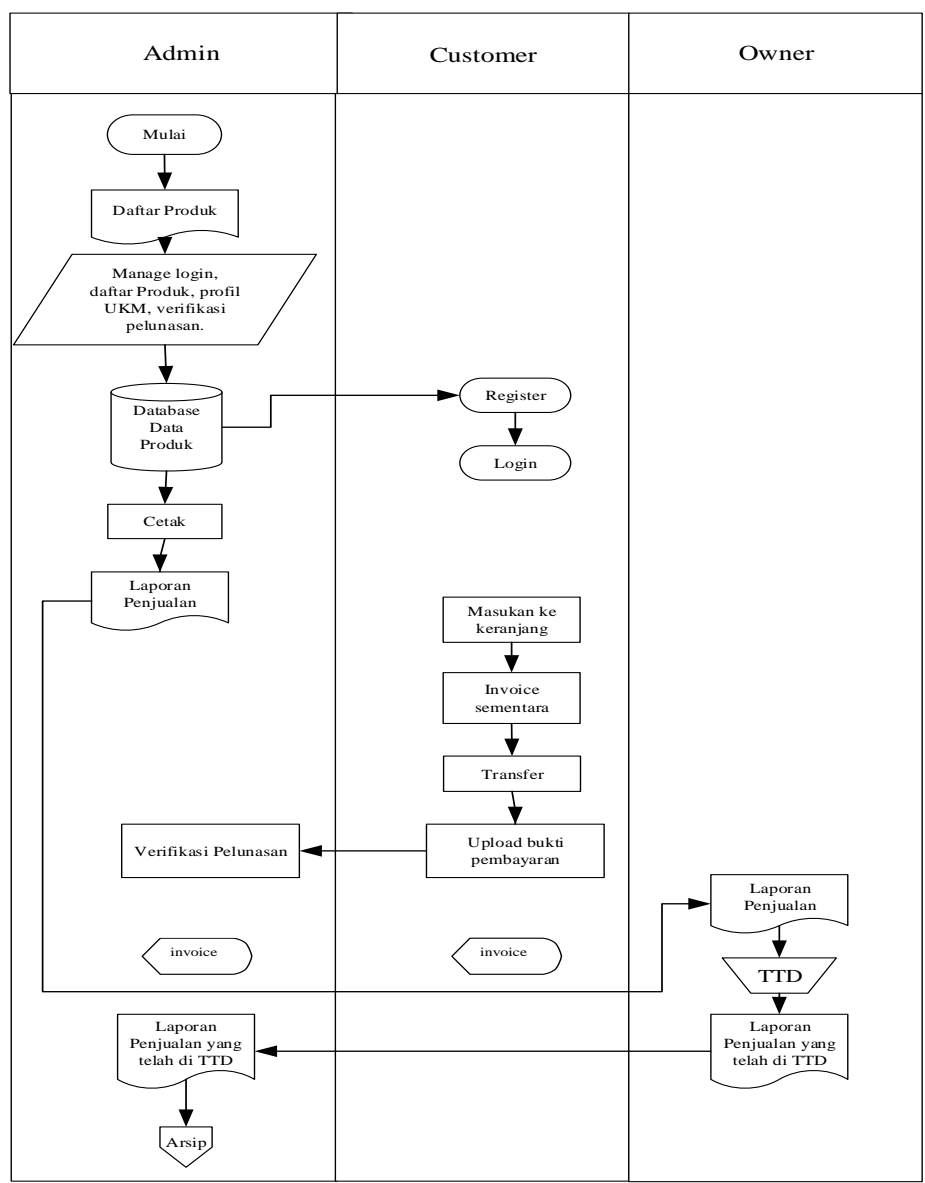

Gambar 2 Aliran Sistem Informasi Baru

Aliran sistem informasi yang baru merupakan perbaikan dari aliran sistem informasi lama, dengan mengubah proses penjualan dari manual menjadi online. Berikut adalah aliran sistem informasi yang baru :

1. Mulai

2. Admin me-manage data produk, profil UKM, User, dan login.

3. Data Produk di input menggunakan bahasa pemrograman $p h p$ dan database MySQL

4. Data Produk disimpan di dalam Database

5. Customer melakukan registrasi untuk membuat akun baru

6. Customer masuk ke menu login. 
7. Customer memilih produk dan memasukan produk ke keranjang.

8. $\quad$ Customer mendapatkan invoice sementara

9. Customer melakukan konfirmasi pembayaran dan mentransfer uang pembelian produk

10. Customer meng-upload bukti pembayaran

11. Admin memverifikasi pembayaran

12. Setelah Admin memverifikasi pembayaran akan muncul invoice penjualan

13. Admin mencetak laporan penjualan dan memberikan laporan poenjualan ke owner

14. Owner menandatangani laporan penjualan dan memberiokan kembali kepada admin

15. Admin mengarsipkan laporan poenjualan yang telah ditandatangani oleh owner.

\subsection{Data flow diagram ( DFD )}

\section{Diagram Konteks}

1. Memanage data customer

2. Verifikasi pelunasan

Admin

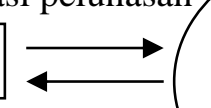

1. Data Customer

2. Data penjualan

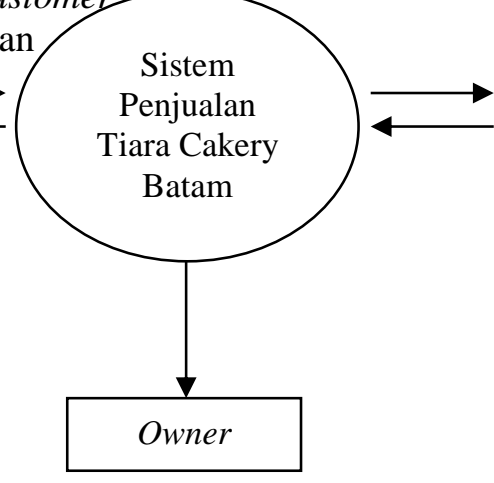

1. Data penjualan produk

Customer

1. Registrasi

2. Pemesanan

3. Input, output, delete data barang

4. lihat barang yang dibeli

5. Upload bukti

1. Lihat laporan penjualan produk

2. Lihat data customer

\subsection{DFD level 0, 1 dan 2}

\section{Gambar 3 Diagram Konteks}

1. Olah data pelanggan/User

2. Approve pesanan

1. Data pelanggan

2. Data penjualan

1. Pemesanan

2. Lihat harga

3. Upload resi

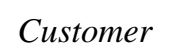

Sistem

penjual

2. Invoice

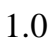
Manage

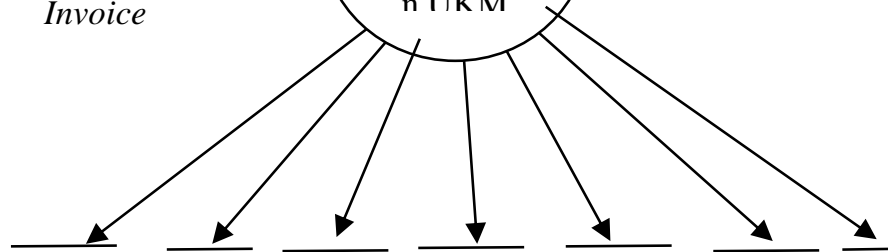

Custemer Produk Kategori Beliveryarea AkunBank Checkout Cart

Gambar 4 DFD Level 0, 1 dan 2

\subsection{Perancangan Entity Relationship Diagram (ERD)}




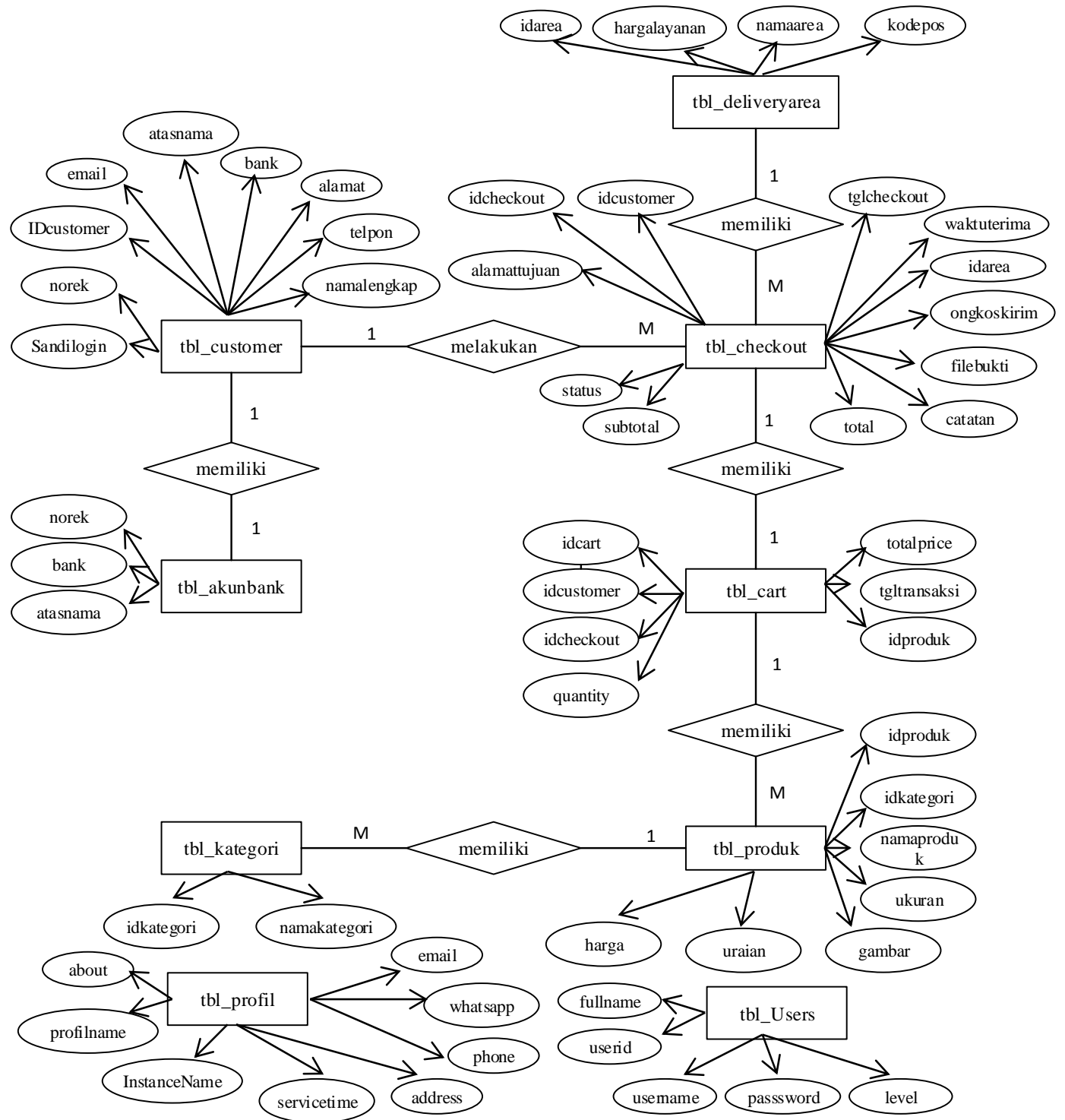

Gambar 5 Entity Relationship Diagram

\subsection{Rancangan Database}

Rancangan Database ini adalah proses pembuatan struktur tabel yang digunakan dalam penyimpanan data pada aplikasi yang dibuat. Struktur data yang digunakan pada aplikasi ini menggunakan MySQL dan berikut adalah rancangan tabel-tabel yang digunakan.

1. tbl_user

Database : db_tiaracake

Primarykey : UserID

Deskripsi : Menyimpan data user

Tabel 1 tbl_user

\begin{tabular}{|c|c|c|c|}
\hline Nama Field & Type & Size & Keterangan \\
\hline UserID & int & 11 & Primarykey \\
\hline Fullname & Varchar & 30 & \\
\hline Username & Varchar & 15 & \\
\hline Password & Text & - & \\
\hline Level & Int & 1 & \\
\hline
\end{tabular}

2. tbl_profil

Database : db_tiaracake 

Berbasis Web pada UKM Tiara Cakery Batam

Primarykey : ProfilName

Deskripsi : menyimpan data profil

Tabel 2 tbl_profil

\begin{tabular}{|c|c|c|c|}
\hline Nama Field & Type & Size & Keterangan \\
\hline ProfilName & Varchar & 10 & Primarykey \\
\hline InstanceName & Varchar & 30 & \\
\hline Service Time & Varchar & 255 & \\
\hline Address & Varchar & 255 & \\
\hline Email & Varchar & 30 & \\
\hline Phone & Varchar & 20 & \\
\hline WhatsApp & Varchar & 20 & \\
\hline About & Text & - & \\
\hline
\end{tabular}

3. tbl_produk

Database : db_tiaracake

Primarykey : IDProduk

Deskripsi : menyimpan data produk

Tabel 3 tbl_produk

\begin{tabular}{|c|c|c|c|}
\hline Nama Field & Type & Size & Keterangan \\
\hline IDProduk & Int & 11 & Primarykey \\
\hline IDKategori & Varchar & 10 & \\
\hline NamaProduk & Varchar & 30 & \\
\hline Ukuran & Varchar & 30 & \\
\hline Harga & Int & 11 & \\
\hline Uraian & Text & - & \\
\hline Gambar & Varchar & 16 & \\
\hline
\end{tabular}

4. tbl_kategori

Database : db_tiaracake

Primarykey : IDKategori

Deskripsi : menyimpan data Kategori

Tabel 4 tbl_kategori

\begin{tabular}{|c|c|c|c|}
\hline Nama Field & Type & Size & Keterangan \\
\hline IDKategori & Varchar & 10 & Primarykey \\
\hline NamaKategori & Varchar & 30 & \\
\hline
\end{tabular}

5. tbl_deliveryarea

Database : db_tiaracake

Primarykey : IDArea

Deskripsi : menyimpan data Deliveryarea

Tabel 5 tbl_Deliveryarea

\begin{tabular}{|c|c|c|c|}
\hline Nama Field & Type & Size & Keterangan \\
\hline IDArea & Int & 4 & Primarykey \\
\hline NamaArea & Varchar & 50 & \\
\hline KodePos & Varchar & 7 & \\
\hline HargaLayanan & Int & 11 & \\
\hline
\end{tabular}

6. tbl_Customer

Database : db_tiaracake

Primarykey : IDCustomer

Deskripsi : menyimpan data Customer

Tabel 6 tbl_Customer

\begin{tabular}{l|l|l|l} 
Nama Field & Type & Size & Keterangan \\
\hline
\end{tabular}




\begin{tabular}{|c|c|c|c|}
\hline IDCustomer & Varchar & 20 & Primarykey \\
\hline NamaLengkap & Varchar & 50 & \\
\hline Alamat & Varchar & 100 & \\
\hline Email & Varchar & 30 & \\
\hline Telpon & Varchar & 15 & \\
\hline Norek & Varchar & 25 & \\
\hline Bank & Varchar & 10 & \\
\hline AtasNama & Varchar & 30 & \\
\hline SandiLogin & Text & - & \\
\hline
\end{tabular}

7. tbl_Checkout

Database : db_tiaracake

Primarykey : IDCheckout

Deskripsi : menyimpan data Checkout

Tabel 7 tbl_Checkout

\begin{tabular}{|c|c|c|c|}
\hline Nama Field & Type & Size & Keterangan \\
\hline IDCheckout & Varchar & 20 & Primarykey \\
\hline IDCustomer & Varchar & 20 & \\
\hline TanggalCheckout & Date & - & \\
\hline MetodePengiriman & Varchar & 8 & \\
\hline WaktuTerima & DateTime & - & \\
\hline IDArea & Varchar & 4 & \\
\hline AlamatTujuan & Varchar & 100 & \\
\hline Catatan & Varchar & 50 & \\
\hline OngkosKirim & Int & 11 & \\
\hline SubTotal & Int & 11 & \\
\hline Total & Int & 11 & \\
\hline Status & Varchar & 10 & \\
\hline FileBukti & Varchar & 25 & \\
\hline
\end{tabular}

8. tbl_akunbank

Database : db_tiaracake

Primarykey : Norek

Deskripsi : menyimpan data akunbank

Tabel 8 tbl_akunbank

\begin{tabular}{|c|c|c|c|}
\hline Nama Field & Type & Size & Keterangan \\
\hline Norek & Varchar & 25 & Primarykey \\
\hline Bank & Varchar & 10 & \\
\hline AtasNama & Varchar & 30 & \\
\hline
\end{tabular}

9. tbl_Cart

Database : db_tiaracake

Primarykey : IDCart

Deskripsi : menyimpan data Cart

Tabel 9 tbl Cart

\begin{tabular}{|c|c|c|c|}
\hline Nama Field & Type & Size & Keterangan \\
\hline IDCart & Int & 11 & Primarykey \\
\hline IDCustomer & Varchar & 20 & \\
\hline IDProduk & Int & 11 & \\
\hline Quantity & Int & 3 & \\
\hline Totalprice & Int & 11 & \\
\hline TanggalTransaksi & Date & - & \\
\hline IDCheckOut & Varchar & 20 & \\
\hline
\end{tabular}

\subsection{Desain Menu}
a.
Halaman Produk Kami

JR : JURNAL RESPONSIVE Teknik Informatika, Sekolah Tinggi Teknik Ibnu sina - Batam 

Berbasis Web pada UKM Tiara Cakery Batam

Halaman produk pada program penjualan online ini meliputi beberapa tampilan yaitu, kategori produk, harga produk, gambar produk dan login.

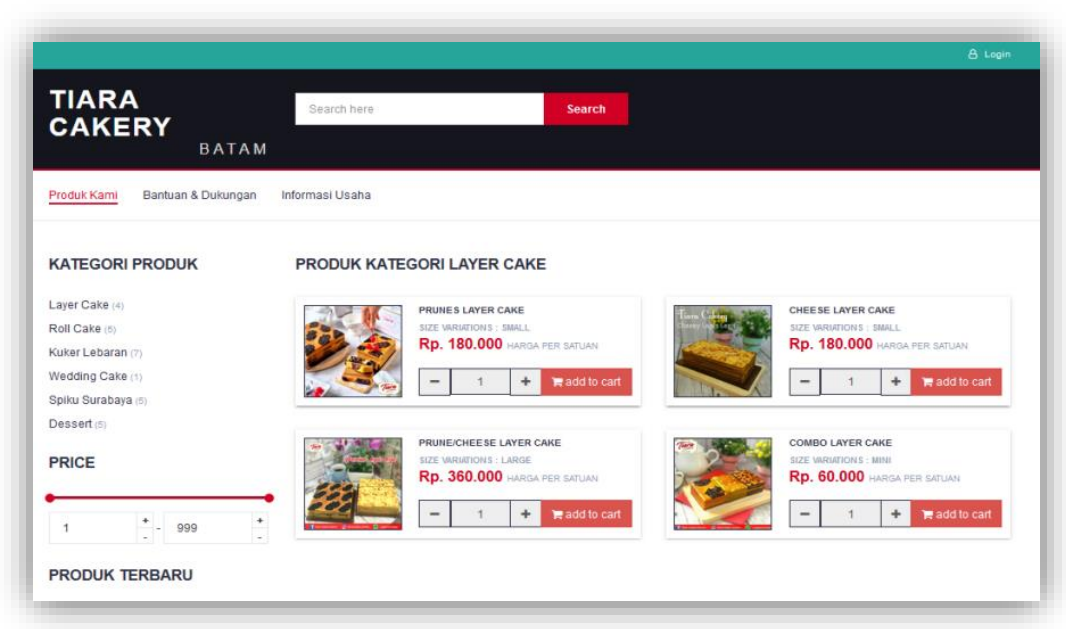

\section{Gambar 6 Halaman Produk Kami}

b. Halaman Login

Sebelum melakukan pembelian, customer akan melakukan login terlebih dahulu untuk bisa melakukan pembelian produk.

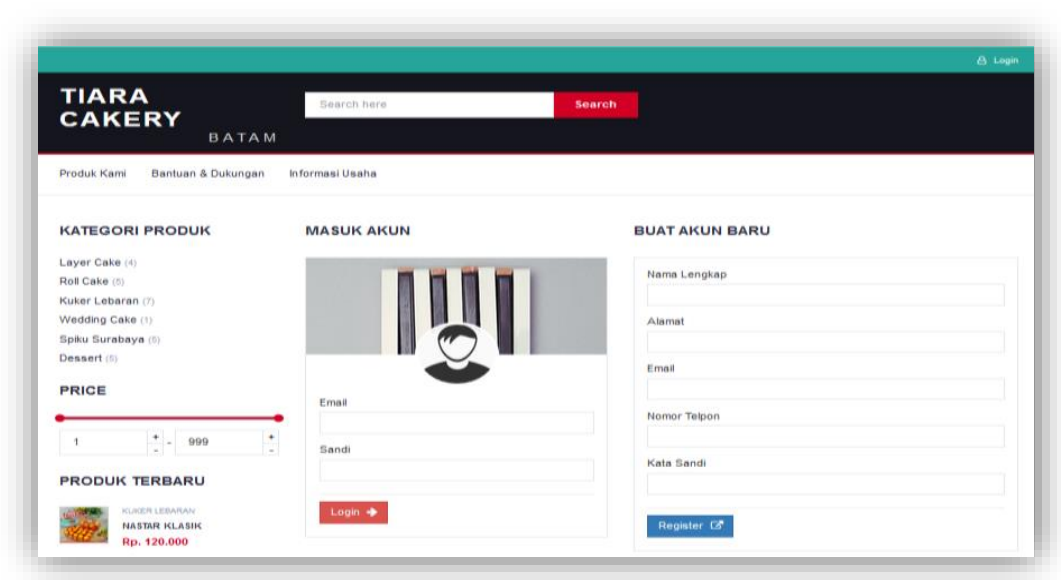

Gambar 7 Halaman Login

c. Halaman My Cart / keranjang belanja

Setelah pemesanan sukses, masuk ke halaman My Cart untuk melihat produk yang telah dipilh 


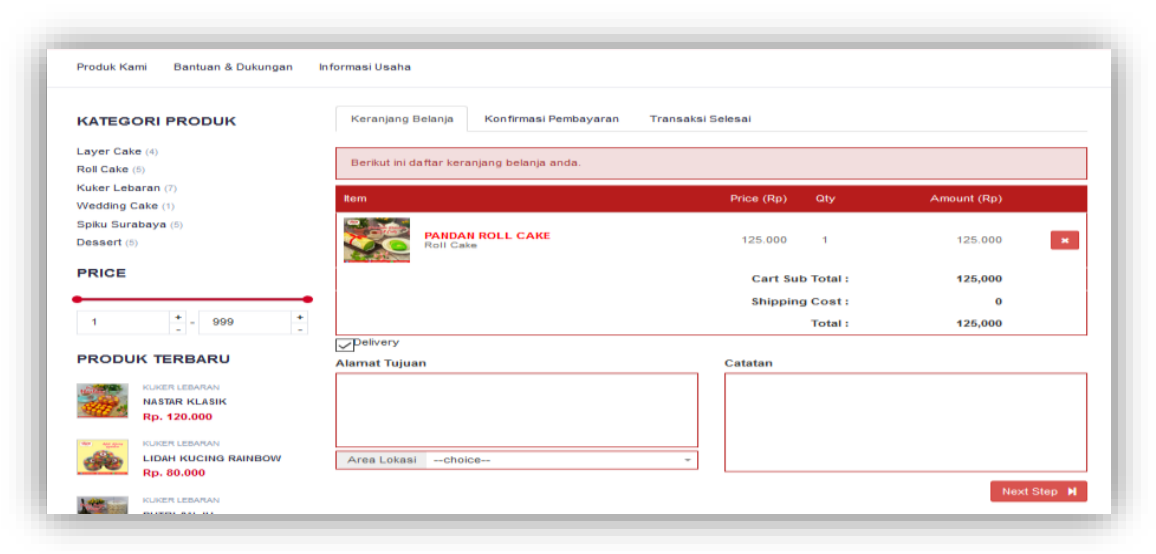

Gambar 8 Halaman My Cart

\section{SIMPULAN}

Berdasarkan uraian dan penjelasan bab-bab sebelumnya maka penulis dapat mengambil sebuah kesimpulan yaitu penjualan pada UKM Tiara Cakery Batam berbasis web dengan mengimplementasikan aplikasi yang dirancang dengan menggunakan bahasa pemrograman $p h p$ dan database MySQL dapat mempermudah UKM Tiara Cakery Batam untuk melakukan penjualan dan dapat membantu mempromosikan produk yang mereka miliki kepada konsumen dan dengan adanya aplikasi ini maka konsumen dapat dengan mudah melihat semua produk dan info tentang UKM Tiara Cakery Batam.

\section{SARAN} lain :

Dalam penulisan Tugas Akhir ini, ada beberapa saran yang dapat penulis sampaikan antara

1. Untuk menjamin sistem berjalan dengan baik, maka harus dilakukan pemeliharaan dan perawatan komputer. Terlebih kepada komputer admin.

2. Penulis berharap dapat terus melakukan pengembangan baik dari segi kelengkapan data, fitur tambahan serta sistem keamanan yang lebih baik lagi.

\section{DAFTAR PUSTAKA}

Anggraeni., Dwi, F. (2013). Pengembangan Usaha Mikro, Kecil dan Menengah (UMKM) Melalui Fasilitasi Pihak Eksternal dan Potensi Internal (Studi Kasus Pada Kelompok Usaha" Emping Jagung" di Kelurahan Pandanwangi Kecamatan Blimbing Kota Malang). Jurnal Administrasi Publik, , 1.6: 1286-1295.

Hartiwi., Yessi. (2017). Analisis Dan Implementasi Sistem Informasi Penjualan Berbasis Web Pada Scarlet Butik. JURNAL ILMIAH MEDIA SISFO, 11.1: 752-766.

Henny, H., Fanny, M. (2008). Analisis dan Perancangan Sistem Informasi Penjualan. Jurnal Ichsan Gorontalo, 3.2: 1555-1569.

Hermawan., Rudi., Utomo, \&Victor, G. (2016). Sistem Informasi Penjadwalan Kegiatan Belajar Mengajar Berbasis Web. Bianglala Informatika, 4.2. 
Indah., Ika Nur. (2013). Pembuatan Sistem Informasi Penjualan Pada Toko Sehat Jaya Elektronik Pacitan. Speed-Sentra Penelitian Engineering dan Edukasi, 12.1.

Kartika, M., Finnia, Et Al. (2014) Analisis Dan Perancangan Sistem Informasi Akutansi Penjualan Dan Penerimaan Kas Pada Pt. Tembaga Mulia Semanan, Tbk.. Phd Thesis. Binus

Liatmaja., Rizka., Wardati, \& Indah U., (2013) Sistem Informasi Akademik Berbasis Web Pada Lembaga Bimbingan Belajar Be Excellent Pacitan. IJNS-Indonesian Journal on Networking and Security, 2.2.

Nurcahyono, Fendi. (2017). Pembangunan aplikasi penjualan dan stok barang Pada toko nuansa elektronik pacitan. Speed-Sentra Penelitian Engineering dan Edukasi, 4.3.

Setyabudhi, A. L. (2017). Perancangan Sistem Informasi Pengolahan Data Absensi dan Pengambilan Surat Cuti Kerja Berbasis Web. JR: JURNAL RESPONSIVE Teknik Informatika, l(1).

Suci., Yuli, R. (2017) Perkembangan UMKM (Usaha mikro kecil dan menengah) di Indonesia. Cano Ekonomos, 6.1: 51-58.

Udi, et al. Penerapan Metode SDLC Waterfall Dalam Pembuatan Sistem Informasi Akademik Berbasis Web Studi Kasus Pondok Pesantren Al-Habib Sholeh 